\title{
Investigation of the Prevalence of Depression in Patients with Chronic Obstructive Pulmonary Disease in Hamadan in 2018
}

\author{
Forough Nadi' ${ }^{1}$, Mohammad Ahmadpanah², Nasim Karimi ${ }^{3}$, Ebrahim Nadi, ${ }^{4}$ \\ ${ }^{1}$ General Practitioner, Hamadan University of Medical Sciences, Hamadan, Iran \\ ${ }^{2}$ Professor of Cognitive Sciences , Behavioral Disorders and Substance Abuse Research Center, Hamadan University of \\ Medical Sciences, Hamadan, Iran \\ ${ }^{3}$ MSc in Biostatistics, Clinical Research Development Unit of Shahid Beheshti Hospital, Hamadan, Iran \\ ${ }^{4}$ Professor, Department of Internal Medicine, School of Medicine, Hamadan University of Medical Sciences, Hamadan, Iran
}

* Corresponding Author: Ebrahim Nadi, Department of Internal Medicine, School of Medicine, Hamadan University of Medical Sciences, Hamadan, Iran.Email: ebrahim_nadi@yahoo.com

\begin{tabular}{|c|c|}
\hline & Abstract \\
\hline $\begin{array}{l}\text { Received: } 19.06 .2018 \\
\text { Accepted: } 10.11 .2018\end{array}$ & \multirow{10}{*}{$\begin{array}{l}\text { Background and Objective: Chronic obstructive pulmonary disease } \\
\text { (COPD) is a worldwide health problem with increasing prevalence. It is } \\
\text { often associated with negative health outcomes, including depression } \\
\text { Therefore, the aim of this study was to determine the prevalence of } \\
\text { depression in patients with COPD. } \\
\text { Materials and Methods: This cross-sectional study with a descriptive- } \\
\text { analytic design was conducted on } 103 \text { patients referring to the respiratory } \\
\text { disease clinic and admitted to the pulmonary disease department of Shahid } \\
\text { Beheshti teaching Hospital, Hamadan, Iran from April to September } 2018 \\
\text { The inclusion criteria were the diagnosis of severe and very severe COPD } \\
\text { according to the medical history, physical examination, and standarc } \\
\text { spirometric methods. The patients with lack of bereavement, trauma, and the } \\
\text { use of antidepressant drugs were excluded from the study. Depression levels } \\
\text { were measured using } 21 \text {-items Beck II depression questionnaire. } \\
\text { Results: The results of the study showed that } 57 \text { patients ( } 55.3 \% \text { ) were males } \\
\text { and } 46 \text { cases ( } 44.7 \% \text { ) were females. The majority of the subjects (33\%) were } \\
\text { in the age group of } 50-59 \text { years old. According to the results, the prevalence } \\
\text { of depression in the study population was } 66 \% \text {. There was a significan } \\
\text { relationship between spirometric parameters of forced expiratory flow at } 25 \\
75 \% \text { of the pulmonary volume, forced expiratory volume at } 1 \text { second and } \\
\text { COPD severity (P=0.024, } P=0.003 \text { ). } \\
\text { Conclusion: With regard to the high prevalence of depression among people } \\
\text { with severe and very severe COPD, it is necessary to consider psychological } \\
\text { counseling for patients. }\end{array}$} \\
\hline \multirow{10}{*}{$\begin{array}{l}\text { How to Cite this Article: } \\
\text { Nadi F, Ahmadpanah M, Karimi } \\
\text { N, Nadi E. Investigation of the } \\
\text { Prevalence of Depression in } \\
\text { Patients with Chronic Obstructive } \\
\text { Pulmonary Disease in Hamadan } \\
\text { in 2018. Avicenna J Clin Med. } \\
\text { 2018; 25(3): 170-176. DOI: } \\
\text { 10.21859/ajcm.25.3.170 }\end{array}$} & \\
\hline & \\
\hline & \\
\hline & \\
\hline & \\
\hline & \\
\hline & \\
\hline & \\
\hline & \\
\hline & $\begin{array}{l}\text { Keywords: Chronic Obstructive Pulmonary Disease, Depression, } \\
\text { Epidemiology }\end{array}$ \\
\hline
\end{tabular}




\title{
بررسى ميزان شيوع افسردىى در افر اد مبتلا به بيمارى انسدادى مزمن ريه در همدان طى سال rar
}

\author{
فروغ نادى'، محمد احمديناهَ، نسيم كريمى"، ابراهيم نادى ؟." \\ دكترى حرفهاى يزشكى، دانشخاه علوم يزشكى همدان، همدان، ايران

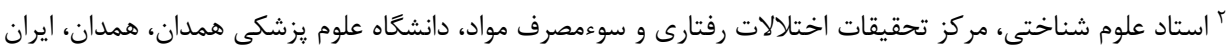

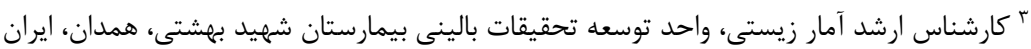

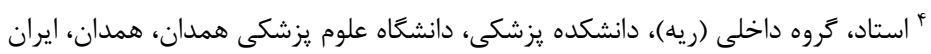

* نويسنده مسئول: ابراهيم نادى، گروه داخلى (ريه)، دانشكده يزشكى، دانشكاه علوم يزشكى همدان، همدان، ايران. ايميل: ebrahim_nadi@yahoo.com

\begin{tabular}{|c|c|}
\hline \multicolumn{2}{|l|}{ ״كيده } \\
\hline سابقه و هدف: بيمارى انسدادى مزمن ريه (COPD: Chronic Obstructive Pulmonary Disease) & 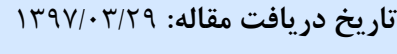 \\
\hline يكى مشكل مرتبط با سلامتى در سراسر جهان است كه شيوع روزافزونى دارد و اغلب با ٍيامدهاى منفى سلامت & 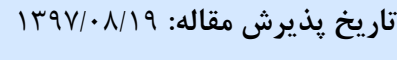 \\
\hline مبتلا به جمله افسردگى همراه مى باشد. در اين ارتباط، مطالعه حاضر با هدف تعيين شيوع افسردگى در بيماران & تمامى حقوق نشر براى دانشكاه علوم \\
\hline مواد و روشها: اين مطالعه مقطعى كه از نوع تو صيفى- تحليلى مىبا شد، از فروردين تا شهريور ماه سال & \\
\hline 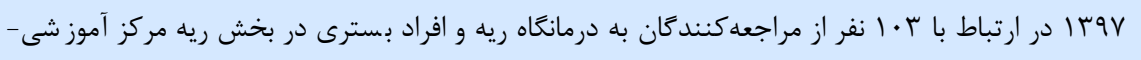 & \\
\hline درمانى شهيد بهشتى همدان انجام شد. افرادى كه COPD شديد و بسيار شديد براساس شرح حال، معاينه & \\
\hline و بر مبناى روشهاى استاندارد ا سيِيرومترى در آنها تشخيص داده شده بود وارد مطالعه شدند. معيارهاى & \\
\hline خروج نيز عبارت بودند از: نداشتن غم داغديدگى و يا حادثه ناكوار و عدم استفاده از داروهاى ضد افسردىى. & \\
\hline بايد عنوان نمود كه اطلاعات با استفاده از يرسشنامه ال سؤالى افسردگى Beck II سنجيده شدند. & \\
\hline 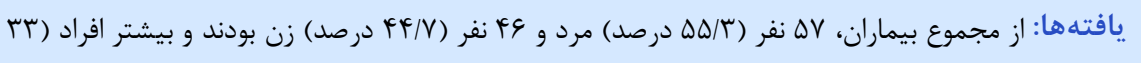 & \\
\hline 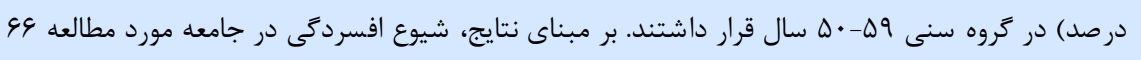 & \\
\hline در صد بود. شايان ذكر ا ست كه بين پارامترهاى اسِيرومترى 25-75 Forced Expiratory Flow at ) FEF & \\
\hline g) (Forced Expiratory Volume at 1 Second) FEV1 , (25-75\% of the Pulmonary Volume & \\
\hline 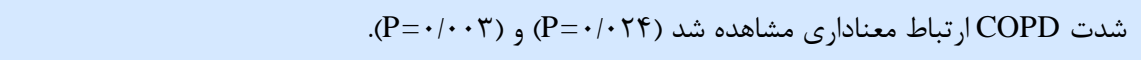 & \\
\hline نتيجه & \\
\hline مىرسد كه لازم است مشاورههاى روانشناسى براى مبتلايان به COPD در نظر كرفته شود. & \\
\hline
\end{tabular}

\begin{abstract}
مى ماند [ب] بيمارى انسدادى مزمن ريه (COPD) يك مشكل مرتبط با

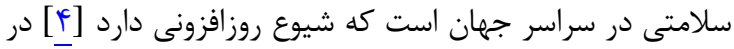

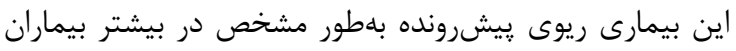

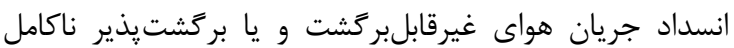

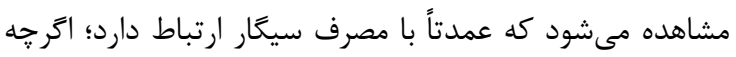

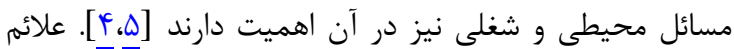

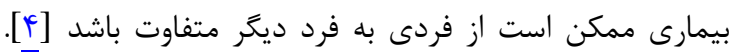

مقلهمه افسردكى يكى از شايعترين اختلالات روانى در سراسر جهان

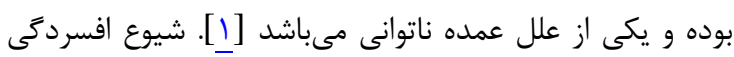

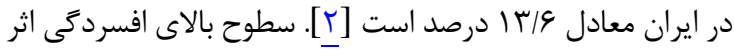

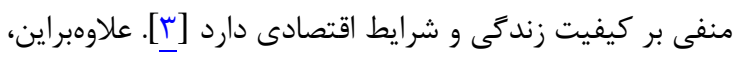

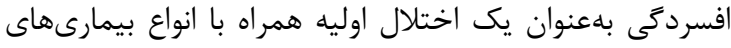

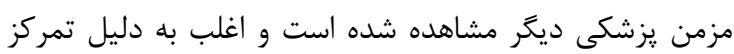

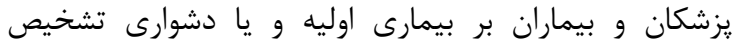

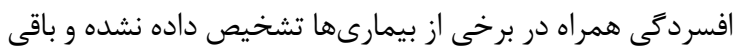


درمانكاه ريه و افراد بسترى در بخش ريه مركز آموزشى - درمانى

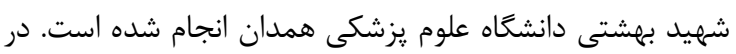

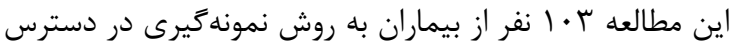

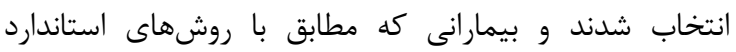

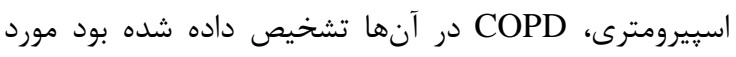

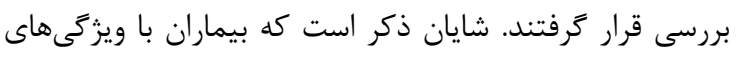

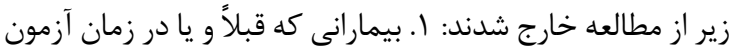

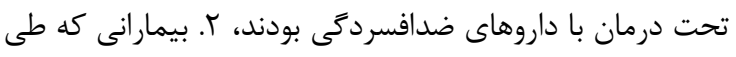

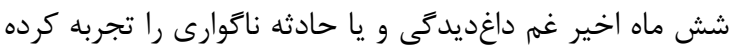

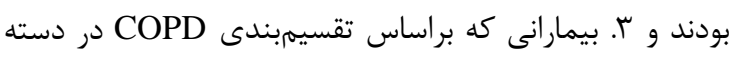
ضعيف و متوسط قرار داشتند.

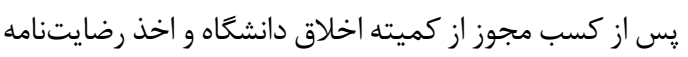

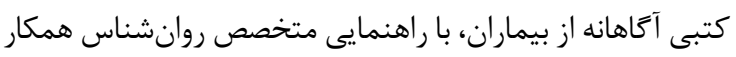

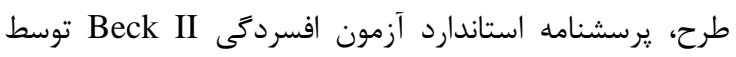
مجرى طرح در اختيار بيماران قرار داده شد و با تفهيم جزئيات

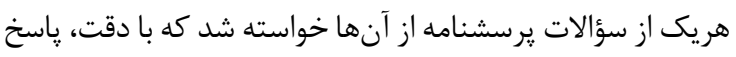

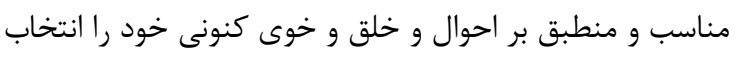

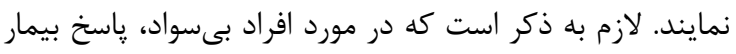

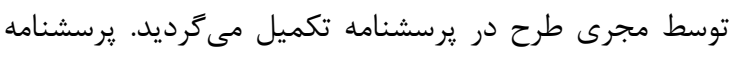

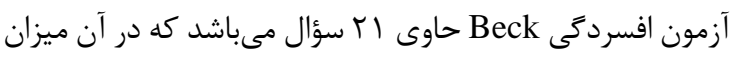

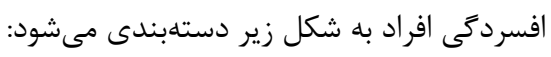

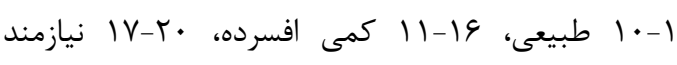

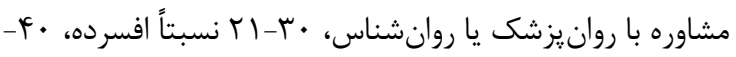

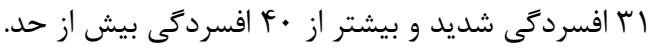

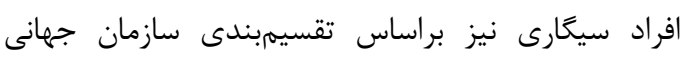
بهداشت به سه دسته تقسيم شدند:

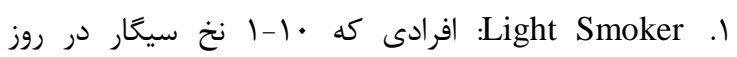
مى كشند. r. Average Smoker: افرادى كه 19-11 نخ سيعار در روز مى كشند. r. Heavy Smoker: افرادى كه • ب نخ و بيشتر سيعار در روز مى كشند. از سوى ديكر، روشهاى استاندارد اسِيرومترى كه براساس آنها COPD تشخيص داده شد، يارامترهاى تنفسى شامل: FEF25-75 FEV1 (Forced Vital Capacity) FVC Forced Expiratory Flow at 25-75\% of the ) و و FEV1/FVC و بودند كه با استفاده از (Pulmonary Volume دستخاه اسييرومتر (شركت Vitalograph انگلستان) و تحت ونت

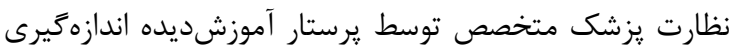

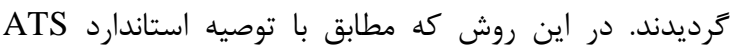
مىباشد، بهمنظور ارزيابى (American Thoracic Society) اثرات داروهاى گشادكننده برونش، آموزشهاى لازم در مورد عدم

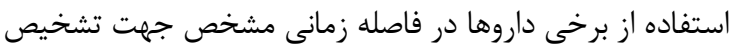
دقيق بيمارى به بيماران ارائه شد.
COPD موجب ناتوانىها و مشكلات سلامت جهانى مىشود كه مىتوانند منجر به تحميل هزينه و صرف سرمايههاى زيادى گر ماتوند

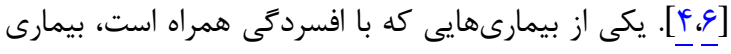

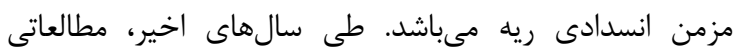

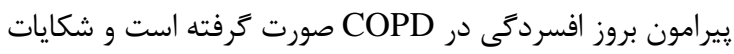

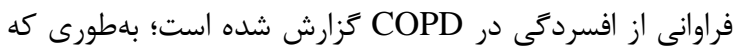

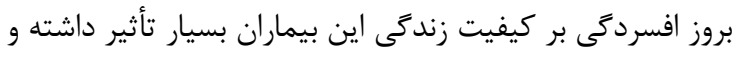

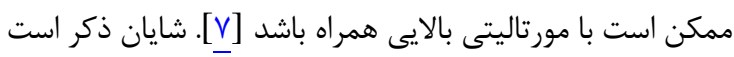

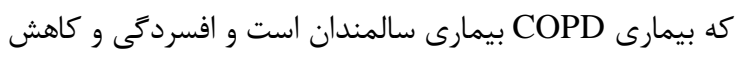
اكسيرن بر كيفيت زندگى اين بيماران تأثير مى حذارد.

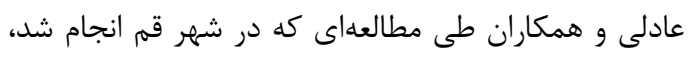

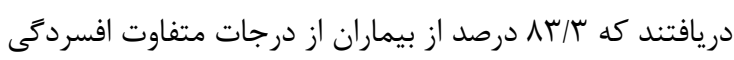

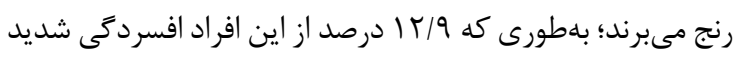
و يا افسردگى بيش از حد داشتند. در اين بررسى افسردى إنى

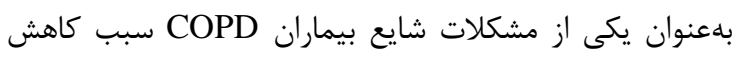

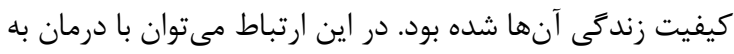

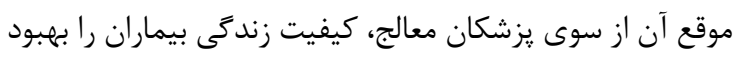
بخشيد [ᄉ]. استيج و همكاران نيز در يزوهشى به اين مهرم دست يافتند

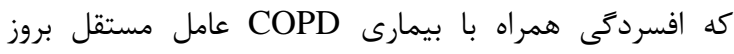

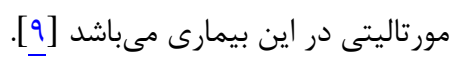

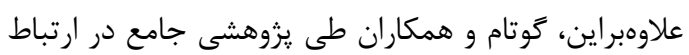

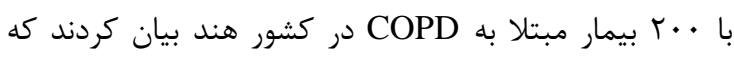

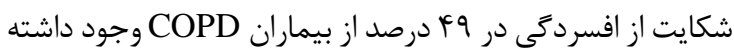

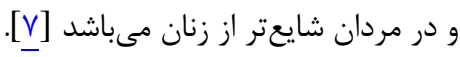

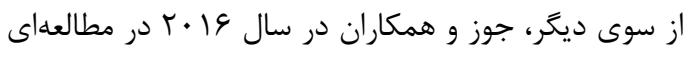

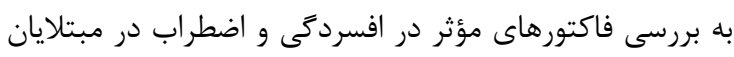

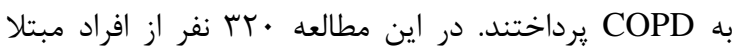

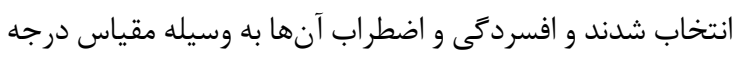
افسردكى بيمارستانى سنجيده شد. نتايج نشان داد كه إنه

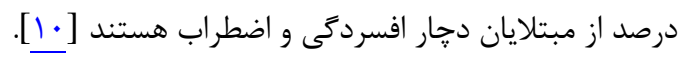
بلهور كلى، بيمارىهاى طبى يكى از دلايل ايجاد افسردى إنى إنى

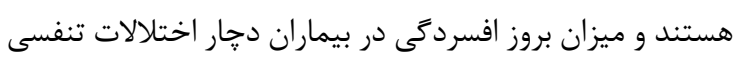

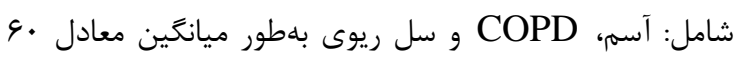

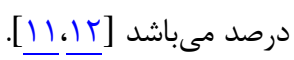

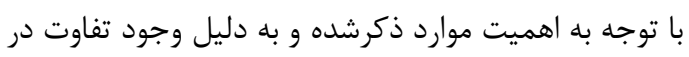

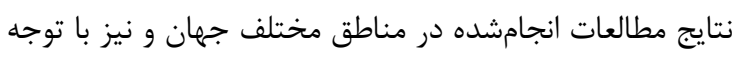

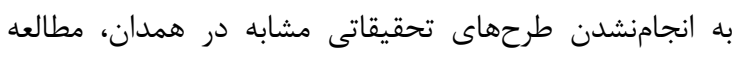

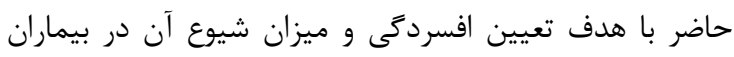
مبتلا به بيمارى نارسايى مزمن ريه صورت كرفت تعرين

\section{مواد و روش ها}

مطالعه مقطعى حاضر از نوع توصيفى- تحليلى بوده و از

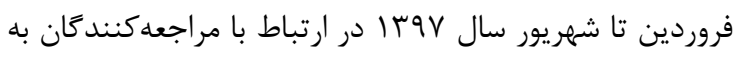


افسردكى و جنسيت وجود ندارد. با توجه به نتايج مطالعه، شيوع

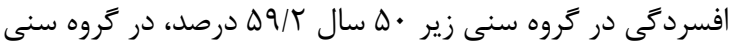
Q 9 - D سال ه

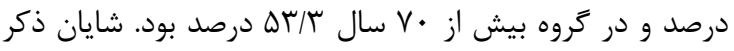

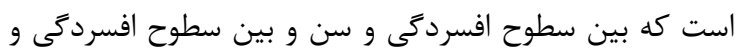
شغل رابطه معنادارى وجود نداشت.

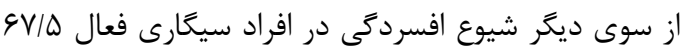

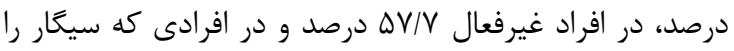

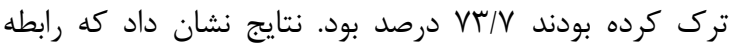
معنادارى بين سطوح افسردگى و سابقه مصرف سيكار، ميزان

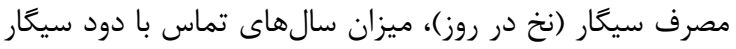
(غيرفعال) و وضعيت Biomass Smoke وجود نداشت.

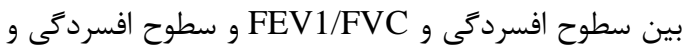

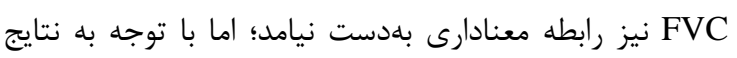
جدول r رابطه بين سطوح افسردىى و FEV1 معنادار مى بـاشد.

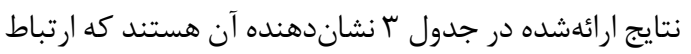

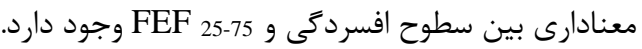
همانطور كه ملاحظه مىشود، ارتباط معنادارى بين سطوح

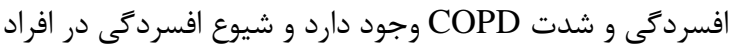
با COPD شديد در مجموع • ع درصد و در افراد با COPD بسيار

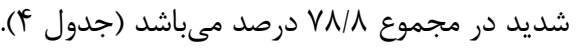

در هايان بلهنظور بررسى ارتباط بين ويزگَى هاى فردى و بالينى

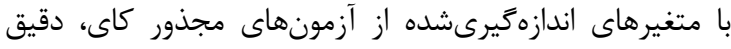

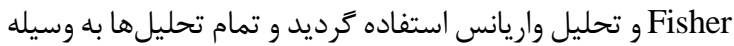
نرمافزار 16 SPSS در سطح معنادارى ه • • •> انجام شد.

1. بافته ها

توصيف ويزگى هاى جمعيتشناختى بيماران مورد مطالعه در جدول ا ارائه شده است. بر مبناى نتايج در ب • ا بيمار مورد بررسى ميانگين (انحراف

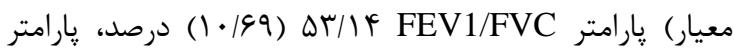

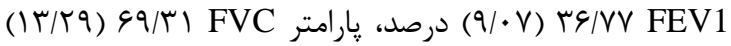

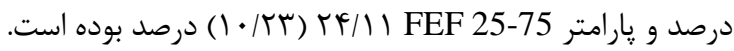

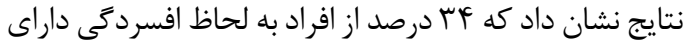

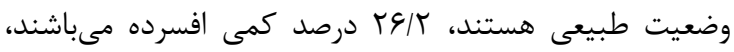

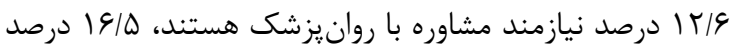

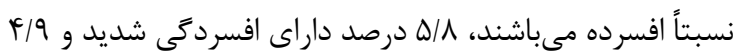
درصد داراى افسردگى بيش از حد هستند. بهطور كلى، شيوع افسردكى در افراد مبتلا به بيمارى مزمن انسدادى رئ رئ معادل 94 درصد مى باشد. بايد خاطرنشان ساخت كه افسردگى بين زنان هN/A درد درصد و در مردان VI/9 درصد مى باشد و رابطه معنادارى بين سطوح

جدول ا: توزيع فراوانى مبتلايان به بيمارى مزمن انسدادى ريه براساس ويزگى هاى جمعيتشناختى

\begin{tabular}{|c|c|c|c|}
\hline درصد & تعداد & & \\
\hline$F F / V$ & fq & \multirow{2}{*}{ 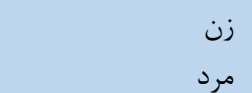 } & \multirow{6}{*}{ سن (سال) } \\
\hline$\Delta \Delta / \Gamma$ & $\Delta V$ & & \\
\hline$r G / T$ & TV & كمتر از •ـه & \\
\hline 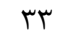 & ry & $\Delta q-\Delta \cdot$ & \\
\hline$r \varepsilon / T$ & TV & $99-9$. & \\
\hline $\mid f / 9$ & 10 & V. بالاى V & \\
\hline$\Lambda / \Lambda$ & 9 & آزاد & \multirow{7}{*}{ 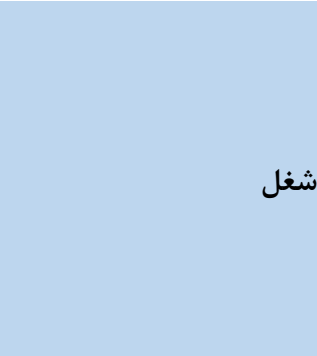 } \\
\hline $9 / 9$ & v & كارگر & \\
\hline $1 \Delta / V$ & 19 & كشاورز & \\
\hline$r F / r$ & ro & خانهدار & \\
\hline$T F / D$ & $r \Delta$ & كارمند & \\
\hline$r / 9$ & r & مهندسى & \\
\hline $9 / 9$ & $\checkmark$ & بيكار & \\
\hline$r q / \Lambda$ & f. & فعال & \multirow{3}{*}{ سابقه مصرف سيگار } \\
\hline FT/V & pq & غيرفعال & \\
\hline$I V / \Delta$ & 19 & ترك كرده & \\
\hline$|N /|^{e}$ & 19 & خفيف (1-• (1) & \multirow{3}{*}{ 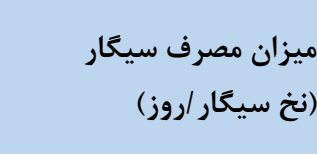 } \\
\hline$r / 9$ & f & متوسط (11-19) & \\
\hline$\Delta / / \Delta$ & Q & زياد (•r نخ و بيشتر) & \\
\hline$r / 9$ & r & زير ·r & \multirow{3}{*}{ 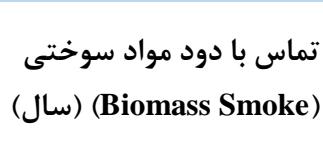 } \\
\hline r & ry & $\Delta \cdot \Delta r$. & \\
\hline $1 / 9$ & rq & بيش از ••ه & \\
\hline
\end{tabular}


جدول ץ: رابطه بين FEV1 با سطوح افسردىى در مبتلايان به بيمارى مزمن انسدادى ريه

\begin{tabular}{|c|c|c|c|}
\hline \multirow{2}{*}{ آماره آزمون (معنادارى) } & \multicolumn{2}{|c|}{ FEV1 } & \multirow{2}{*}{ سطوح افسردَى } \\
\hline & انحر اف معيار & ميانَين & \\
\hline \multirow{6}{*}{$(\cdot / \cdot r) r / q r \Delta$} & "N/TA & Tq/Tा & طبيعى \\
\hline & $\Lambda / D Q$ & एq/11 & كمى افسرده \\
\hline & $V / F$. & $\mathrm{rV} / \cdot \cdot$ & نيازمند مشاوره با روانيزشك \\
\hline & $1 \cdot / 94$ & 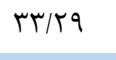 & به نسبت افسرده \\
\hline & ( & TV/D. & افسردحى شديد \\
\hline & $\Delta / 11$ & rN/A. & افسردگى بيش از حد \\
\hline
\end{tabular}

جدول سا: رابطه بين FEF25-75 با سطوح افسردىى در مبتلايان به بيمارى مزمن انسدادى ريه

\begin{tabular}{|c|c|c|c|}
\hline \multirow{2}{*}{ آماره آزمون (معنادارى) } & \multicolumn{2}{|c|}{ FEF 25-75 } & \multirow{2}{*}{ سطوح افسردَى } \\
\hline & انحراف معيار & ميانكين & \\
\hline \multirow{6}{*}{$(\cdot / \cdot T Y) T / V T I$} & $* q / r q$ & "TQ/TI & طبيعى \\
\hline & $11 / 1$. & TE/TT & كمى افسرده \\
\hline & $11 / 91$ & $r \varepsilon / T \wedge$ & نيازمند مشاوره با روانيزشك \\
\hline & $9 / 49$ & tr/AT & به نسبت افسرده \\
\hline & r/AD & IQ/Ar & افسردگى شديد \\
\hline & $r / 4 q$ & $1 T / \Lambda$ & افسردگى بيش از حد \\
\hline
\end{tabular}

جدول ₹أ: رابطه بين شدت COPD با سطوح افسردىى در مبتلايان به بيمارى مزمن انسدادى ريه

\begin{tabular}{|c|c|c|c|c|c|}
\hline \multirow{2}{*}{$\begin{array}{l}\text { آماره آزمون } \\
\text { (معنادارى) }\end{array}$} & \multicolumn{2}{|c|}{ COPD بسيار شديد } & \multicolumn{2}{|c|}{ COPD } & \multirow{2}{*}{ سطوح افسردَى } \\
\hline & درصد & 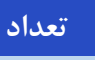 & درصد & 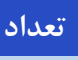 & \\
\hline \multirow{6}{*}{$(\cdot / \cdot r \Delta) 11 / r q r$} & $r I / r$ & v & f. & r人 & طبيعى \\
\hline & $T Y / T$ & $\wedge$ & $r V / l$ & 19 & كمى افسرده \\
\hline & $9 / 1$ & r & $\mid f / r$ & 1. & نيازمند مشاوره با روانيزشك \\
\hline & $r M / T$ & v & $\mid x / r$ & 1 . & به نسبت افسرده \\
\hline & $|r /|$ & f & $r / 9$ & r & افسردگى شديد \\
\hline & $\mid r / T$ & f & $1 / 4$ & 1 & افسردحى بيش از حد \\
\hline
\end{tabular}

يكى از دلايلى كه شيوع بيشتر افسردگى رادر بين مردان توجيه

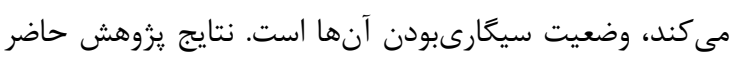

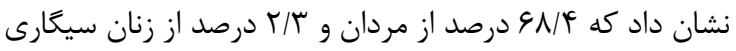

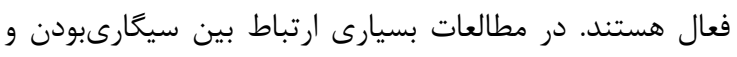

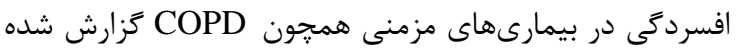

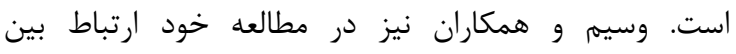

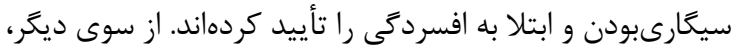

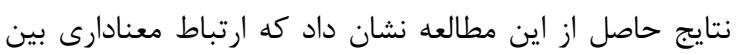

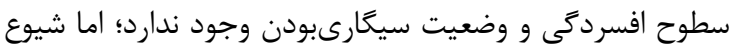

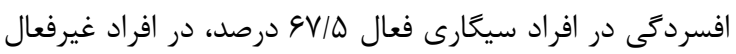

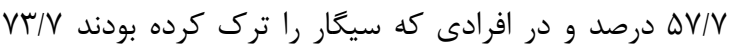
درصد بود. شايان ذكر است كه بر مبناى نتايج ارتباط معنادارى درى
براساس نتايج حاصل از اين مطالعه مشاهده شد كه شيوع

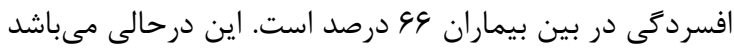

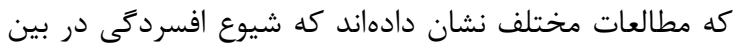

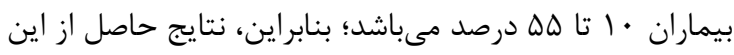

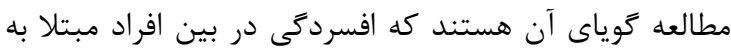
COPD در استان همدان از بسيارى از مطالعات و جوامع بالاتر

علاوهبراين، نتايج نشان دادند كه شيوع افسردگى در زنان هN/V

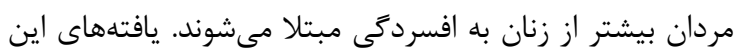

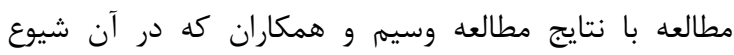

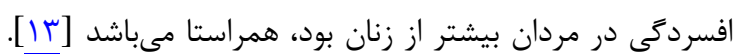


بسيار شديد، بيشتر از افراد با COPD شديد بود. اين يافته با

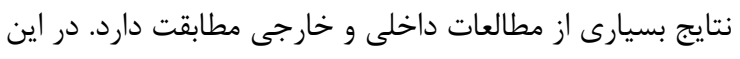

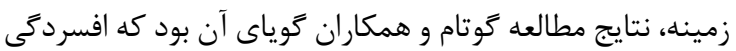

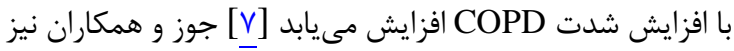

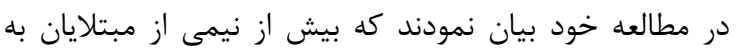

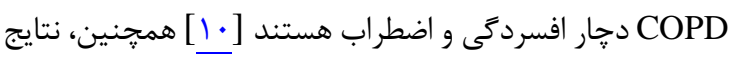

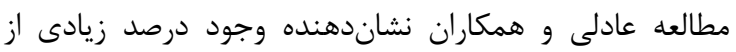

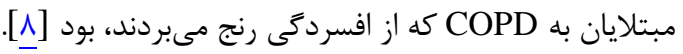

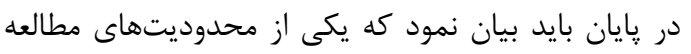

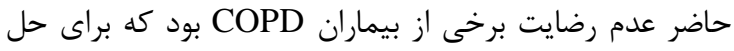

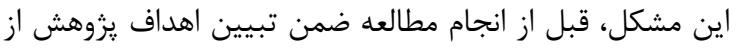
آنها رضايتنامه آكاهانه اخذ كرديد.

\section{نتيجه تيرى}

يافتههاى اين مطالعه نشان داد كه ميزان شيوع افسردىى در

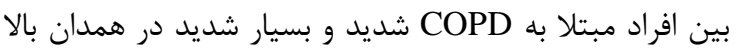

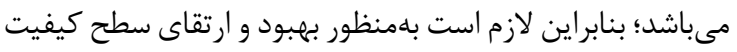

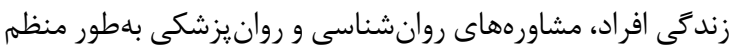

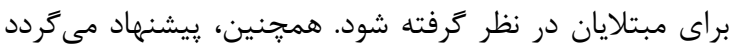

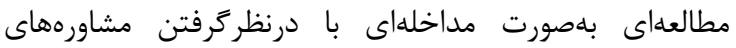

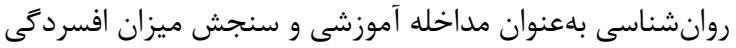

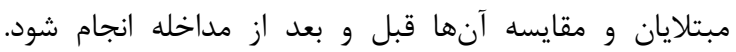
علاوهبراين، توصيه مى گردد سنجش كيفيت زندگى مبتلايان به مبه

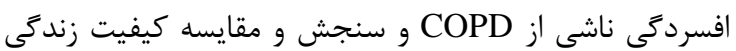
آنها در يك مطالعه مورد شاهدى با درنظرگرفتن افراد مبتلا به COPD

\section{تشك و قلفروانى}

اين مقاله بركرفته از طرح يزوهشى دانشجويى مصوب دانشعاه علوم يزشكى همدان به شماره بدينوسيله نويسندكان مراتب قدردانى خود را از بيماران به دله بليل

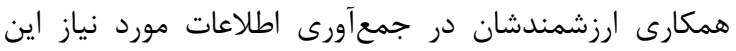

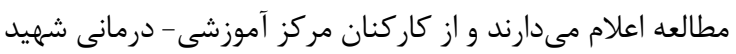

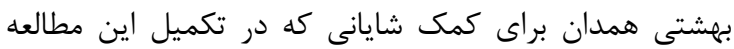

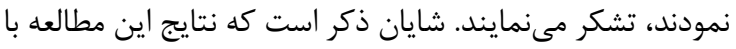

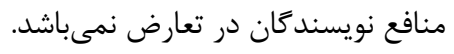

\section{REFERENCES}

1. Brostow DP, Petrik ML, Starosta AJ, Waldo SW. Depression in patients with peripheral arterial disease: a systematic review. Eur J Cardiovasc Nurs. 2017;16(3):181-93. PMID: 28051339 DOI: $10.1177 / 1474515116687222$

2. Nasiri M, Hosseini H, Sakhaei Y, Tabrizi N, Yazdani Cherati J, Abedini M. Prevalence of psychiatric disorders in patients with multiple sclerosis in Mazandaran, Iran. J Mazandaran Univ Med Sci. 2016;26(140):60-70. [Persian]

3. Schlosser RJ, Gage SE, Kohli P, Soler ZM. Burden of illness: a systematic review of depression in chronic rhinosinusitis.
بين افسردگى و وضعيت سيگارى غيرفعال وجود نداشت؛ اما

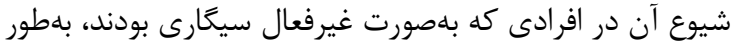

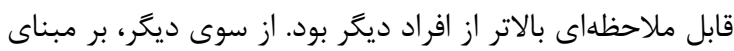

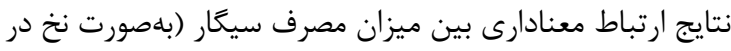

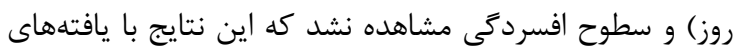

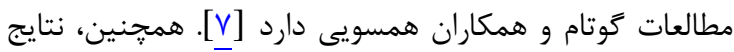

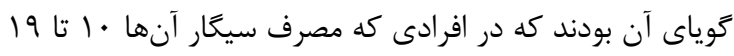
نخ در روز (مصرف متوسط) است، افسردىى بيشترى مشاهده

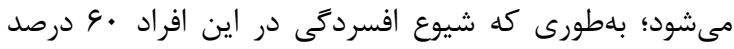

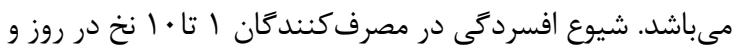

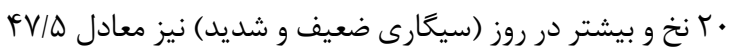
و و FV/T درصد بود كه ميزان قابل توجهى است.

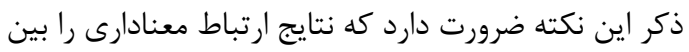

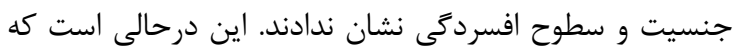

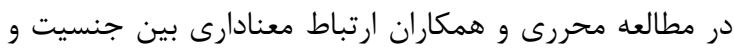

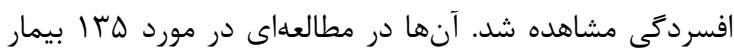

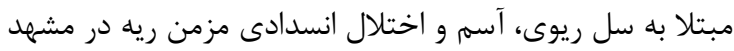

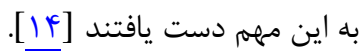

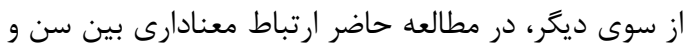

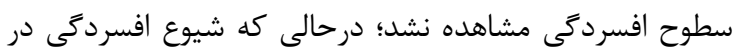

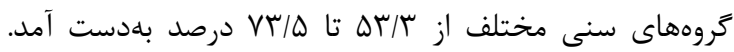

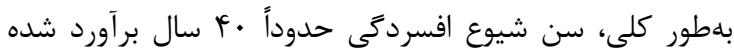

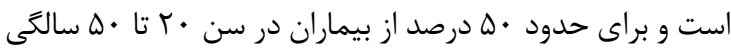

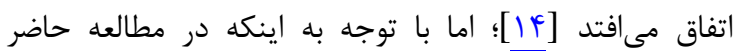

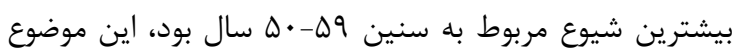

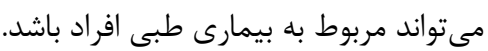

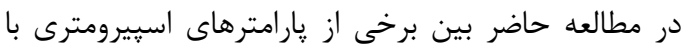

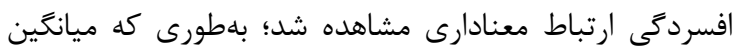

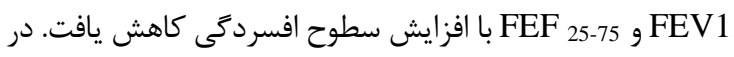
اين ارتباط، در مطالعه جوز و همكاران ارتباط معنادارى بين

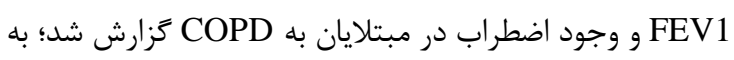
نحوى كه افراد COPD كه همزمان اضطراب داشتند، داراى

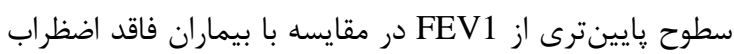
بودند [1][ب. از ديخر يافتههاى مطالعه حاضر مشاهده ارتباط معنادار بين

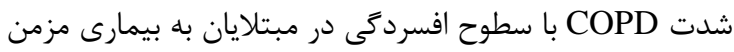

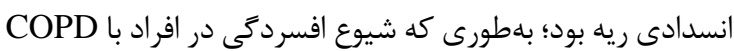

Am J Rhinol Allergy. 2016;30(4):250-6. PMID: 27456594 DOI: 10.2500/ajra.2016.30.4343

4. Breda Cushen RM, Summer R. Chronic obstructive pulmonary disease. $2^{\text {nd }}$ ed. New York: International Encyclopedia of Public Health; 2017.

5. Mehrabi SA, Sadin MR, Ghauomi SM. Determining the most suitable spirometric parameters to differentiate chronic obstructive pulmonary disease (COPD) from asthma. Armaghane Danesh. 2010;14(4):76-87.

6. Goodarzi MT, Abdi M, Tavilani H, Nadi E, Rashidi M. 
Adenosine deaminase activity in COPD patients and healthy subjects. Iran J Allergy Asthma Immunol. 2010;9(1):7-12. PMID: 20548128 DOI: 09.01/ijaai.712

7. Gautam AK, Kumar A, Gupta AK, Kushwaha BK, Yadav P, Pandey AK. Assessment of depression among chronic obstructive pulmonary disease (COPD) patients at rural tertiary care centre of Northern India. Int $J$ Res Med Sci. 2017;5(9):4017-20. DOI: 10.18203/2320-6012.ijrms20173974

8. Adeli SH, Faker H, Mozafari A, Heidari A, Mirzapour M, Asadi M. Frequency of depression in 207 patients with COPD in Qom city, 2008. Qom Univ Med Sci J. 2011;5(2):34-8. [Persian]

9. Stage KB, Middelboe T, Stage TB, Sørensen CH. Depression in COPD-management and quality of life considerations. Int J Chron Obstruct Pulmon Dis. 2006;1(3):315-20. PMID: 18046868

10. Jose AK, Chelangara DP, Shaji KS. Factors associated with anxiety and depression in chronic obstructive pulmonary disease. Int J Res Med Sci. 2016;4(4):1074-9.

11. Reilly J. Silverman. Chronic obstructive pulmonary disease. In: Kasper D, Hauser S, Jameson JL, Fauci A, Longo L, editors. Harrison's principles of internal medicine. $19^{\text {th }}$ ed. New York: McGraw Hill; 2015. P. 1700.

12. Urrutia I, Aguirre U, Pascual S, Esteban C, Ballaz A, Arrizubieta I, et al. Impact of anxiety and depression on disease control and quality of life in asthma patients. $J$ Asthma. 2012;49(2):201-8. PMID: 22308974 DOI: 10.3109/02770903.2011.654022

13. Waseem SM, Hossain M, Azmi S, Rizvi SA, Ahmad Z, Zaidi SH. Assessment of anxiety and depression in COPD patients: a pilot study. Age. 2012;43:13-4.

14. Moharreri F, Rezaeitalab F, Sadjadi SAr, Sarjamei S. The comparison of anxiety and depression among patients with bronchial asthma, chronic obstructive pulmonary disease and lung tuberculosis. J Fundamental Mental Health. 2013;15(58):82-90. [Persian] 